Sabrina Nunes dos Santos ${ }^{1}$

Mariana de Oliveira Araujo ${ }^{2}$

Nildo Batista Mascarenhas ${ }^{1}$

Taciane Oliveira Bet Freitas ${ }^{2}$

\section{Percepcão de estudantes de Enfermagem sobre os sentidos e significados do trabalho gerencial do enfermeiro}

RESUMO| Introdução: A função gerencial integra o processo de trabalho do enfermeiro nos vários níveis de atenção à saúde e busca garantir a realização de uma assistência de qualidade e eficiente, sendo necessário para a sua execução conhecimento técnico e científico. Objetivos: Compreender a percepção de estudantes de enfermagem sobre os sentidos e significados do trabalho gerencial do enfermeiro e identificar a(s) dificuldade(s) e/ou facilidade(s) na execução do trabalho gerencial do enfermeiro na percepção de discentes de enfermagem. Métodos: Trata-se de uma pesquisa qualitativa, na qual a coleta de dados foi realizada através da técnica da entrevista semiestruturada e teve como participantes dez estudantes de enfermagem. Para análise dos dados, foi utilizada a Técnica de Análise de Conteúdo. Resultados: O trabalho gerencial do enfermeiro relacionase à organização do trabalho e do serviço de saúde e ao planejamento das atividades prestadas. No desenvolvimento do trabalho gerencial, os estudantes identificaram como facilidades a capacitação profissional, o trabalho em equipe e o diálogo. Como dificuldades, citou-se o desafio do enfermeiro em realizar a associação do trabalho assistencial e gerencial, a sobrecarga de trabalho, a relação de liderança sobre a equipe e a falta de recursos materiais. Conclusão: A articulação entre o trabalho gerencial e o assistencial deve ser enfatizada e construída no cotidiano do trabalho, dado que ambos constituem o trabalho do enfermeiro no Brasil e valorizam essa profissão.

Palavras-chave | Administração de Serviços de Saúde; Enfermeiro; Assistência à Saúde.

${ }^{1}$ Universidade do Estado da Bahia. Senhor do Bonfim/BA, Brasil.

${ }^{2}$ Universidade Estadual de Feira de Santana. Feira de Santana/BA, Brasil. 


\section{INTRODUÇÃO|}

O processo de trabalho do enfermeiro se constitui no modo indissociável de como ele executa as atividades assistenciais e gerenciais, as quais articulam saberes filosóficos, políticos e técnicos ${ }^{1}$.

No contexto do trabalho gerencial, o enfermeiro deve utilizar métodos específicos para a coordenação do cuidado e/ou do serviço de saúde, dado que uma de suas atribuições é participar do planejamento, organização, direção, coordenação, execução e avaliação dos serviços de saúde/enfermagem².

O trabalho gerencial está presente na prática do enfermeiro desde a sua formação profissional, sendo imprescindível para o seu exercício profissional nos vários níveis de atenção à saúde ${ }^{3}$, tendo como principais objetivos a coordenação da equipe de saúde/enfermagem, a organização e o direcionamento das ações executadas nos serviços de saúde e a garantia da qualidade da assistência prestada ao usuário.

Ao executar o trabalho gerencial, o enfermeiro utiliza alguns instrumentos, dentre eles a supervisão, o planejamento e a avaliação, os quais são utilizados para enfrentar os problemas surgidos no cotidiano do trabalho e subsidiar a tomada de decisão. Assim, por meio desses instrumentos, o enfermeiro poderá alcançar resultados satisfatórios no seu processo de trabalho, o que demonstra a importância do gerenciamento ${ }^{4}$.

A ação gerencial é fundamental no processo de organização de serviços de saúde e na efetivação de políticas sociais, em especial as de saúde, e isso requer um grande preparo do profissional enfermeiro ${ }^{3}$, bem como a utilização de ferramentas para solucionar os problemas existentes, gerenciar conflitos no trabalho e estabelecer regras e rotinas no processo de trabalho para operacionalizar a produção do cuidado.

Além disso, comungamos com Senna e outros ${ }^{5}$ que na produção do cuidado não deve haver dissociação entre as dimensões assistencial e gerencial do processo de trabalho do enfermeiro, cujo produto é o cuidado individual ou coletivo.

Por isso, destacamos a relevância das práticas gerenciais no processo de trabalho do enfermeiro, as quais devem ser constantemente avaliadas e planejadas. Isso revela a importância de se desenvolver competências e habilidades gerenciais nos cursos de graduação em enfermagem, de modo a formar enfermeiros que reconheçam a importância do trabalho gerencial.

De acordo com as Diretrizes Curriculares Nacionais ${ }^{6}$, a formação do enfermeiro busca dotar o profissional de conhecimentos necessários para o desempenho das seguintes competências e habilidades gerais: atenção à saúde, tomada de decisão, comunicação, liderança, administração e gerenciamento e educação permanente.

Além disso, de acordo com a Lei 7498, de 25 de junho $1986^{7}$, que regulamenta o exercício da enfermagem e dá outras providências, privativamente compete ao enfermeiro exercer cargos de direção e organização de órgãos de enfermagem, sendo necessários, para tanto, conhecimentos e instrumentos que o auxiliem no desempenho do gerenciamento dos serviços.

Por isso, é importante conhecer a percepção dos estudantes de enfermagem sobre o trabalho gerencial do enfermeiro, de modo a contribuir para aquisição de conhecimento e para a sua formação enquanto futuro profissional.

Isso posto, delimitou-se a seguinte questão de pesquisa: qual a percepção dos estudantes de enfermagem sobre os sentidos e significados do trabalho gerencial do enfermeiro? Qual(ais) a(s) dificuldade(s) e/ou facilidade(s) percebidas e/ ou vivenciadas na execução do trabalho gerencial do enfermeiro na percepção de discentes de enfermagem?

Com base nesses questionamentos, os objetivos deste estudo foram compreender a percepção de estudantes de enfermagem sobre os sentidos e significados do trabalho gerencial do enfermeiro e identificar a(s) dificuldade(s) e/ou facilidade(s) na execução do trabalho gerencial do enfermeiro na percepção de discentes de enfermagem.

\section{MÉTODOS|}

Trata-se de um estudo descritivo de abordagem qualitativa. O lócus da pesquisa foi uma universidade pública do estado da Bahia, que possui o curso de Bacharelado em Enfermagem. Os participantes foram 10 estudantes de enfermagem, que possuíam idade entre 21 e 40 anos, sendo oito (8) do sexo feminino e dois (2) do sexo masculino, 
que haviam cursado as disciplinas Gerenciamento em Enfermagem I e Gerenciamento em Enfermagem II e encontravam-se no oitavo semestre.

A quantidade de participantes foi definida pelo critério de saturação das falas, que diz respeito à interrupção da inserção de novos participantes no estudo quando os dados coletados demonstram uma regularidade ou repetição no conteúdo ${ }^{8}$. Deste modo, ao finalizar a décima entrevista, percebeu-se que as falas apresentavam reprodução do conteúdo entre si, procedendo-se à interrupção da coleta de dados.

Utilizamos como técnica de coleta de dados a entrevista semiestruturada. A coleta de dados foi realizada nos meses de maio e junho de 2017, após aprovação no Comitê de Ética em Pesquisa da Universidade do Estado da Bahia (UNEB), no dia 04 de maio de 2017, segundo parecer n².046.192 (CAAE 65552017.4.0000.0057).

Após os estudantes de enfermagem aceitarem participar da pesquisa e assinarem o Termo de Consentimento Livre e Esclarecido (TCLE), as entrevistas foram realizadas individualmente, em um local reservado no Campus da universidade, de modo a garantir o anonimato e a privacidade dos participantes, bem como possibilitar que expressassem sua opinião sobre as questões elencadas, as quais seguiam um roteiro específico e foram gravadas em gravador digital e portátil, sendo transcritas posteriormente, com duração em média de seis (6) a 10 minutos.

As falas foram identificadas a partir da ordem de realização das entrevistas, ou seja, a primeira foi identificada como E-1, a segunda E-2 e assim sucessivamente.

Escolhemos como método de análise de dados a Análise de Conteúdo, que compreende um conjunto de "técnicas de pesquisa que permitem tornar replicáveis e válidas inferências sobre dados de um determinado contexto, por meio de procedimentos especializados e científicos" "9:303. Para tanto, usamos as etapas do Método de Análise de Conteúdo propostas por Minayo?.

No primeiro momento, realizamos a pré-análise, quando organizamos o material coletado a partir da leitura flutuante das entrevistas, tomando contato exaustivo com seus conteúdos. Posteriormente, na exploração do material, as informações das entrevistas foram classificadas e codificadas, através de recortes e associações, usando para isso um quadro onde foi feita a síntese horizontal (identificação e agrupamento das falas semelhantes, complementares, divergentes e diferentes) e a vertical (resumo de cada entrevista a partir dos núcleos de sentido apresentados). Por fim, fizemos o tratamento e interpretação dos resultados, quando articulamos os materiais coletados com os referenciais teóricos acerca do tema estudado, emergindo as categorias descritas nos resultados e discussão.

\section{RESULTADOS/DISCUSSÃO |}

O trabalho gerencial do enfermeiro tem como objeto a organização do trabalho e os recursos humanos em enfermagem. Para a execução desse processo de trabalho, são utilizados alguns instrumentos, tais como o planejamento, o dimensionamento de pessoal de enfermagem, o recrutamento e seleção de pessoal, a educação continuada e/ou permanente, a supervisão, a avaliação de desempenho e outros ${ }^{10}$.

$\mathrm{Na}$ perspectiva dos participantes, o trabalho gerencial do enfermeiro traduz-se, principalmente, na organização do processo de trabalho em saúde/enfermagem:

É a forma que o enfermeiro tem de organizar todo o processo de trabalho (E-4).

É a questão da organização, organizar a divisão das tarefas dos trabalhadores, da equipe [...] (E-8).

Esses mesmos sujeitos consideram que o trabalho gerencial é importante para a organização do processo de trabalho em saúde/enfermagem porque torna possível o desenvolvimento das ações assistenciais da equipe de saúde e o atendimento das demandas de saúde dos usuários:

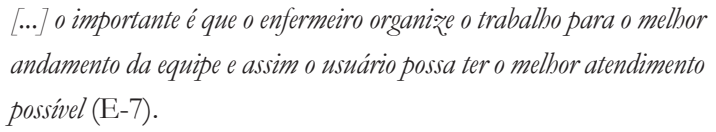
andamento da equipe e assim o usuário possa ter o melhor atendimento possivel (E-7).

É quando o enfermeiro torna tanto a unidade de saúde quanto o trabalho em enfermagem uma realidade [...], propiciando que a unidade tenha recursos materiais, recursos humanos e um trabalbo qualificado para prestar assistência ao paciente [...] (E-10). 
[...] Tipo, manter em ordem uma equipe, né? Manter em ordem os equipamentos que ali oferecem, manter os fins lucrativos da unidade, o que se gasta, o que se perde, é dessa forma eu acho que o trabalho do enfermeiro é (E-1).

Observa-se que o trabalho gerencial do enfermeiro tem como objetivo principal a organização do processo de trabalho em saúde/enfermagem e do serviço de saúde, a fim de assegurar uma assistência em saúde/enfermagem satisfatória e integral aos usuários ${ }^{11}$. Identifica-se também que o trabalho gerencial é um fator de integração da equipe de saúde, sendo que o enfermeiro pode ser considerado um mediador na resolução de possíveis conflitos.

Não se pode deixar de comentar que para os entrevistados o processo de trabalho do enfermeiro envolve a articulação da gerência com a assistência, e essa articulação é fundamental para que os problemas de saúde dos usuários sejam resolvidos da melhor maneira possível.

Apesar de a gerência e de a assistência constituírem o processo de trabalho do enfermeiro, alguns entrevistados consideraram que o trabalho gerencial é uma atividade estritamente burocrática, conforme expresso abaixo:

É coordenar uma unidade desde a parte burocrática, até a parte assistencial, controle dos recursos materiais, medicamentos, recursos bumanos (E-2).

[...] ele vai trabalhar com a parte dos impressos, a organização dos serviços, escala, o andamento da funcionalidade dos serviços prestados em uma determinada unidade (E-6).

[...] é saber coordenar as coisas que têm na instituição desde os insumos até as papeladas burocráticas (E-9).

Essas falas sinalizam que parte dos participantes concebeu o trabalho gerencial de maneira restrita e desconectada do trabalho assistencial. No estudo de Santos e outros ${ }^{4}$, os participantes também conceberam que assistência e gerência são atividades incompatíveis e dissociadas no processo de trabalho do enfermeiro, e o trabalho gerencial foi considerado uma ação de cunho burocrático voltada para o controle dos serviços de saúde e dos trabalhadores.

Outro aspecto extraído da fala dos participantes refere-se ao trabalho gerencial como aspecto identitário do enfermeiro:
É importante porque dá uma identidade pra o enfermeiro, até porque a enfermagem não é só assistência, pois[...] o enfermeiro também pode ser gestor $(\mathrm{E}-2)$.

É de extrema importância, mesmo porque a atividade gerencial é exclusiva do enfermeiro e da enfermeira, então [...] é de extrema importância dentro do serviço de saúde (E-6).

À luz dessas considerações, é preciso reconhecer a importância do trabalho gerencial do enfermeiro, dado que ele articula e integra as ações prestadas pelos demais trabalhadores da saúde, garante a continuidade da atenção à saúde e o atendimento das demandas de saúde dos usuários $^{1 ; 12}$.

Neste sentido, é imprescindível que o enfermeiro execute as atividades gerenciais, que no campo da enfermagem são executadas exclusivamente por esse trabalhador, visto que ele atua como um gerente intermediário, no espaço entre a organização de saúde, os usuários e os demais trabalhadores da saúde, organizando o trabalho em saúde e coordenando o trabalho em enfermagem ${ }^{12}$.

O desenvolvimento de competências gerenciais em enfermagem é essencial para o trabalho do enfermeiro, tais como: liderança, comunicação, administração, formulação e participação de processos decisórios, tomada de decisão e gerenciamento. Deste modo, salienta-se a importância do estabelecimento de competências gerenciais nos currículos de enfermagem e de buscar proporcionar criticidade no processo de ensino ${ }^{13}$.

De acordo com Soares et al. ${ }^{14}$, a execução do trabalho gerencial exige do enfermeiro habilidades diversificadas, especialmente num contexto de diversas mudanças das práticas de saúde e de avanços tecnológicos que têm sido constantemente incorporados ao trabalho em saúde.

Dentre os aspectos facilitadores da execução do trabalho gerencial do enfermeiro, a capacitação foi apontada pelos participantes como um fator que aprimora a leitura da realidade e auxilia no enfrentamento de problemas no cotidiano do trabalho:

As facilidades, elas vêm quando o profissional é bem preparado. Se ele está bem preparado, não vai encontrar tanta dificuldade, e quando encontrar, saberá resolvê-las (E-2). 
Desde que esteja se atualizando constantemente, acredito que o enfermeiro não tenha dificuldade $[\ldots]$ (E-3).

No estudo realizado por Oliveira et al. ${ }^{15}$, evidenciou-se que para o gerenciamento dos serviços de enfermagem em instituições de saúde é fundamental que os enfermeiros possuam competências e habilidades para implementar estratégias a serem aplicadas no processo de trabalho em enfermagem.

Para tanto, a realização de capacitações destinadas às enfermeiras poderá se constituir em uma estratégia que pode contribuir com o fortalecimento do gerenciamento do cuidado ${ }^{16}$.

Cabe ressaltar que uma das atividades do trabalho gerencial é a tomada de decisões em um contexto complexo e envolto de incertezas, como é o caso do trabalho em saúde/enfermagem. Para que isso ocorra, o enfermeiro deve se manter atualizado para analisar os problemas de forma sistematizada e enfrentar as contingências que emergirem do ambiente de trabalho ${ }^{17}$. É necessário também que o enfermeiro facilite a criação de vínculos entre os diferentes trabalhadores da saúde para melhor desenvolver o seu trabalho:

[...] se você criar um vínculo com a equipe e for uma coisa mútua e com respeito, ai o profissional consegue desenvolver (E-8).

Deste modo, a liderança do enfermeiro fortalece a execução do trabalho gerencial, principalmente porque facilita a supervisão da equipe, a criação de vínculos e a articulação das dimensões do trabalho do enfermeiro ${ }^{18}$. Isso faz da gerência uma atividade complexa, permeada também por dificuldades:

Eu acho que tem só dificuldades (E-3).

As facilidades são poucas, aliás eu acho que não têm não (E-5).

Eu acho que não têm facilidades não (E-7).

Eu consigo ver mais as dificuldades (E-9).

Eu acho que só têm dificuldades, no momento eu não consigo enxergar uma facilidade [...], consigo ver mais as dificuldades (E-10).
$\mathrm{Na}$ percepção dos participantes, essas dificuldades estão relacionadas à frágil associação do trabalho gerencial com o trabalho assistencial:

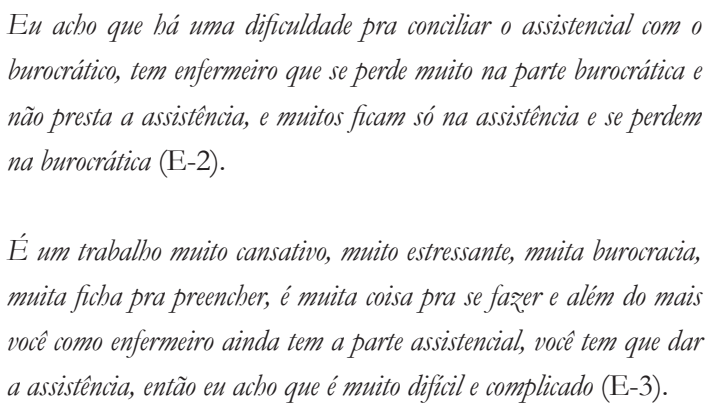
burocrático, tem enfermeiro que se perde muito na parte burocrática e não presta a assistência, e muitos ficam só na assistência e se perdem na burocrática (E-2).

É um trabalbo muito cansativo, muito estressante, muita burocracia, muita ficha pra preencher, é muita coisa pra se fazer e além do mais você como enfermeiro ainda tem a parte assistencial, você tem que dar a assistência, então eu acho que é muito difícil e complicado (E-3).

Como se observa, a desarticulação dos trabalhos gerencial e assistencial desencadeia o afastamento do enfermeiro de uma das dimensões do seu trabalho, conforme foi identificado também por Lima e outros ${ }^{19}$.

Essa evidência relaciona-se à concepção ideológica sobre o trabalho do enfermeiro vigente no campo da enfermagem, a qual separa o trabalho gerencial do trabalho assistencial. Essa dissociação gera conflitos e pode aumentar a insatisfação com o trabalho, já que as enfermeiras e os enfermeiros não se identificam com o seu trabalho e com a sua profissão, não compreendem que a natureza do seu processo de trabalho é assistencial-gerencial, sendo que ambas as dimensões são complementares e interdependentes ${ }^{12}$.

Convém afirmar que a natureza assistencial-gerencial do trabalho da enfermeira não se separa no seu processo de trabalho, sendo falsa a concepção de que a enfermeira assiste ou gerencia, de maneira dicotômica. Em determinado tempo e lugar, uma dimensão do processo de trabalho da enfermeira pode se sobrepor a outra, exigindo que a enfermeira execute ações assistenciais ou gerenciais numa quantidade e intensidade variada, mas direcionadas a um mesmo objetivo, que é produzir ações e serviços ${ }^{12}$.

Vale salientar que, como afirmam Melo, Santos e Leal ${ }^{12}$, o trabalho gerencial é função privativa do enfermeiro, porém ele é um processo coletivo e seu sucesso está relacionado à colaboração desse profissional com a equipe de enfermagem, de saúde e com os demais trabalhadores cujas ações influenciam na assistência do usuário.

Apesar de a interação entre os membros da equipe ser necessária para o desenvolvimento da prática do 
enfermeiro, esta também pode dificultar a execução do trabalho gerencial:

[...] a questão de se trabalhar com outras pessoas porque a gente trabalha com uma equipe e nem sempre a equipe vai querer daquela forma, e ai vai ter todos esses conflitos que vai ter que resolver [...] (E-4).

[...] tem uma resistência dos profissionais, [...] quando chega nessa parte de ter uma autoridade os profissionais eles meio que se fecham um pouco (E-8).

Saber lidar com situações de conflitos é fundamental para a enfermeira e uma de suas atribuições ao exercer o papel de líder. Gerenciar pessoas é apontado como uma das atividades mais difíceis e importante para o êxito da organização, a partir do manejo dos conflitos e das situações envolvidas ${ }^{20}$.

Nessas situações, é primordial respeitar as diferenças socioeconômicas e/ou culturais, buscando desenvolver um bom diálogo, criar vínculo com a equipe e a conquistar a confiança de seus colaboradores. Ao desempenhar a liderança a enfermeira deverá possuir conhecimento, habilidades e atitudes, que busquem promover um ambiente de trabalho mais harmonioso e prazeroso ${ }^{20}$.

Por fim, a sobrecarga de trabalho foi apontada pelos participantes como um fator que também dificulta o desenvolvimento do trabalho gerencial.

[...] acredito que a maior dificuldade acaba sendo [...] a grande quantidade de trabalho que a gente tem, então é bem complicado (E-4).

[...] tem a sobrecarga de trabalho, que além de ter que ser assistencial, tem o gerencial também [...] (E-8).

Além da sobrecarga de trabalho, a escassez de recursos materiais e financeiros também foi destacada pelos entrevistados como uma dificuldade para a gerência do enfermeiro:

Eu acho que a dificuldade está mais financeira e daqueles superiores que estão ali pra ajudar (E-1).

[...] falta de algo na unidade, mas nem sempre depende de você pra poder conseguir, porque precisa de questões de governo, do dono da instituição, [...] então isso dificulta muito (E-9).
O impedimento maior é a gestão, porque [...] no que se trata dos recursos materiais, [...] porque geralmente a gestão não dá esse aparato pra que o enfermeiro possa desenvolver (o gerenciamento) (E-10).

A escassez de recursos materiais é motivo de preocupação para o enfermeiro, dado que afeta a execução do processo de trabalho e compromete a qualidade do cuidado prestado aos usuários ${ }^{21}$.

Esse fato se agrava pelo contexto de precarização do trabalho em que o enfermeiro é submetido, cujas principais características são a diminuição da renda, vínculos trabalhistas frágeis e instáveis, flexibilização dos direitos trabalhistas, prolongamento da jornada de trabalho, insegurança em relação à proteção social, aumento das condições insalubres e perigosas de trabalho, entre outras formas ${ }^{22}$.Tudo isso contribui para que o enfermeiro tenha cada vez menos autonomia e se aliene do seu trabalho.

\section{CONCLUSÃO|}

A partir das falas dos entrevistados, percebemos que o significado do trabalho gerencial do enfermeiro na percepção de estudantes de enfermagem está relacionado à organização do processo de trabalho em saúde/ enfermagem e do serviço de saúde, a fim de assegurar o cuidado integral aos usuários. Ademais, notamos também que os estudantes conceberam que o enfermeiro é responsável, na maior parte das vezes, pela forma como o trabalho em saúde/enfermagem é conduzido.

Outra evidência identificada foi a visão do trabalho gerencial como algo "burocrático" e que afasta o enfermeiro da assistência aos usuários. Isso aponta a necessidade de se articular os trabalhos gerencial e assistencial, dado que ambos são interdependentes e necessários para o alcance da finalidade do processo de trabalho do enfermeiro, o cuidado integral às pessoas.

Em relação às facilidades do processo de trabalho do enfermeiro, identificou-se que os participantes consideraram a capacitação profissional como o instrumento fundamental para o enfrentamento dos problemas e a tomada de decisões no cotidiano do trabalho. Dentre as dificuldades apontadas pelos estudantes, verificou-se que as principais foram a associação do 
trabalho assistencial e gerencial e as precárias condições de trabalho a que os enfermeiros são submetidos.

Com base nisso, defendemos que a articulação entre o trabalho gerencial e o assistencial deve ser enfatizada e construída no cotidiano do labor, dado que ambos constituem a labuta do enfermeiro e valorizam essa profissão.

\section{REFERÊNCIAS |}

1. Leal JAL, Melo CMM. Processo de trabalho da enfermeira em diferentes países: uma revisão integrativa. Rev Bras Enferm. 2018; 71(2):413-23.

2. Conselho Federal de Enfermagem. Resolução nº . 509, de 15 de março de 2016. Atualiza a norma técnica para Anotação de Responsabilidade Técnica pelo Serviço de Enfermagem e define as atribuições do enfermeiro Responsável Técnico [Internet]. Diário Oficial da União 15 mar 2016 [acesso em 02 set 16]. Disponível em: URL: http:/ /www.cofen.gov.br/ resolucao-cofen-no-05092016-2_39205.html.

3. Madureira GC, Santos MF, Santos DSS, Batalha EMSS. Reflexão sobre a enfermagem e o gerenciamento das unidades básicas de saúde. Rev Baiana de Saúde Pública. 2016; 40(4):848-61.

4. Santos JLG, Prochnow AG, Silva DC, Silva RM, Leite JL, Erdmann AL. Prazer e sofrimento no exercício gerencial do enfermeiro no contexto hospitalar. Esc Anna Nery. 2013; 17(1):97-103.

5. Senna MH, Drago LC, Kirchner AR, Santos JLG, Erdmann AL, Andrade SR. Significados da gerência do cuidado construídos ao longo da formação profissional do enfermeiro. Rev Rene. 2014; 15(2):196-205.

6. Brasil. Lei nº 7498, de 25 de junho de 1986. Dispõe sobre a regulamentação do exercício da enfermagem e dá outras providências [Internet]. Diário Oficial da União 26 jun 1986 [acesso em 28 jul 2018]. Disponível em: URL: http://www.planalto.gov.br/ccivil_03/leis/L7498.htm.

7. Ministério da Educação (Brasil). Resolução no 3 , de 7 de novembro de 2001. Institui Diretrizes Curriculares Nacionais do Curso de Graduação em Enfermagem. Diário Oficinal da União 09 nov 2001 [acesso em 28 jul
2018]. Disponível em: URL: http://portal.mec.gov.br/ cne/arquivos/pdf/CES03.pdf.

8. Minayo MCS. O desafio do conhecimento: pesquisa qualitativa em saúde. 12. ed. São Paulo: Hucitec; 2010.

9. Minayo MCS. Pesquisa social: teoria, método e criatividade. 29. ed. Petrópolis: Vozes; 2010.

10. Soares MI, Camelo SHH, Resck ZMR, Terra FS. Saberes gerenciais do enfermeiro no contexto hospitalar. Rev Bras Enferm. 2016; 69(4):676-83.

11. Dellaroza MSG, Tada CN, Haddad MCL, Vannuchi MTO, Mazieiro VG. O ensino de gerência em enfermagem na graduação: uma revisão integrativa. Semina: Ciênc Biol Saúde. 2015; 36(1):149-58.

12. Melo CMM, Santos TA, Leal JAL. Processo de trabalho assistencial-gerencial da enfermeira. In: Vale EG, Peruzzo AS, Felli VEA, organizadoras. Programa de Atualização em Enfermagem (PROENF): ciclo 4. Porto Alegre: Artmed; 2015. p. 45-75.

13. Rosin J, Tres DP, Santos RP, Peres RR, Oliveira JLC. Desenvolvimento de competências gerenciais na enfermagem: experiência entre residentes. Rev Eletr Gestão Saúde. 2016; 7(1):231-46.

14. Soares MI, Camelo SHH, Resck ZMR, Terra FS. Saberes gerenciais do enfermeiro no contexto hospitalar. Rev Bras Enferm. 2016; 69(4):676-83.

15. Oliveira FEL, Fernandes SCA, Oliveira LL, Queiroz JC, Azevedo VRC. A gerência do enfermeiro na estratégia saúde da família. Rev RENE. 2012; 13(4): 834-44.

16. Fermino V, Amestoy SC, Santos BP, Casarin ST. Estratégia Saúde da Família: gerenciamento do cuidado de enfermagem. Rev Eletr Enf. 2017; 19:1-10.

17. Eduardo EA, Peres AM, Almeida ML, Roglio KD, Bernardino E. Análise de modelo de tomada de decisão de enfermeiros gerentes: uma reflexão coletiva. Rev Bras Enferm. 2015; 68(4):668-75.

18. Lanzoni GMM, Meirelles BHS. Liderança do enfermeiro: elemento interveniente na rede de relações 
do agente comunitário de saúde. Rev Bras Enferm. 2013; 66(4):557-63.

19. Lima RS, Dázio EMR, Rosado SR, Lourenço EB. Dificuldades e facilidades no gerenciamento de enfermagem no hospital na perspectiva do enfermeiro. Rev Enferm UFPE. 2014; 8(12):4253-60.

20.Sousa ACD, Silva FS, Espindola JS, Moreira NL, Dragnov PB. Atuação do Enfermeiro nas estratégias para resolução de conflitos. Rev Adm Saúde. 2018; 18(73):1-12

21. Gil RB, Chaves LDP, Laus AM. Gerenciamento de recursos materiais com enfoque na queixa técnica. Rev Eletr Enferm. 2015; 17(1):100-7.

22. Melo CMM, Carvalho CA, Silva LA, Leal JAL, Santos TA, Santos HS. Força de trabalho da enfermeira em serviços estaduais com gestão direta: revelando a precarização. Esc Anna Nery. 2016; 20(3):e20160067.

Correspondência para/Reprint request to:

Mariana de Oliveira Araujo

BR 116, KM 03, Campus universitário,

Universidade Estadual de Feira de Santana,

Feira de Santana/BA, Brasil

CEP: $44031-460$

E-mail:mariana-enf@hotmail.com

Recebido em: 27/09/2018

Aceito em: 06/06/2020 